\title{
A secagem de sementes ${ }^{1}$
}

\author{
Drying of seeds
}

\author{
Danton Camacho Garcia ${ }^{2}$ Antonio Carlos Souza Albuquerque Barros ${ }^{3}$ \\ Silmar Teichert Peske ${ }^{4}$ Nilson Lemos de Menezes $^{5}$
}

\section{- REVISÃo BIBLIOGRÁFICA -}

\section{RESUMO}

A operação de secagem das sementes é fundamental no sistema de produção, pois, além de reduzir o teor de água, para permitir a preservação de sua qualidade fisiológica durante o armazenamento, possibilita a antecipação da colheita evitando perdas de natureza diversa. Na escolha do método de secagem, o fator quantidade de sementes é limitante e, quando necessitamos secar grandes quantidades, é imprescindivel a utilização de secagem artificial, cujos custos de operação estão relacionados, principalmente, com volume, velocidade de secagem e temperatura do ar. Torna-se importante que os operadores tenham consciência das condições de secagem que conseguem proporcionar às sementes, buscando maximizar os benefícios possíveis ou, por outro lado, minimizar ao máximo as inevitáveis e irreversíveis perdas que ocorrem a partir do momento que as sementes atingem sua máxima qualidade, ainda no campo.

Palavras-chave: métodos de secagem, fluxos de ar, sementes.

\section{ABSTRACT}

The drying operation of the seeds is fundamental in the production system because it reduces the tenor of water to allow its physiologic quality preservation during the storage and makes possible the anticipation of the crop avoiding losses of several CAUSE. In the choice of the drying method, the amount seeds factor is limited and, when we need to dry larger amounts the use of artificial drying is indispensable, whose operation costs are related, mainly, with volume, drying speed and temperature of the air. It becomes important that the operators are aware of the drying conditions that they get to provide to the seeds, aiming to maximize the possible benefits or, on the other hand, to minimize to the maximum the inevitable and irreversible losses that happen from the moment that the seeds reach its maximum quality, still in the field.

Key words: drying, airflow, seeds.

\section{INTRODUÇÃO}

A secagem de sementes, além de contribuir para a preservação da qualidade fisiológica durante o armazenamento, possibilita a antecipação da colheita evitando perdas de natureza diversa durante o processo produtivo.

$\mathrm{Na}$ escolha do método de secagem, o fator quantidade de sementes é limitante e, quando necessitamos secar grandes quantidades, é imprescindível a utilização de secagem artificial, cujos custos de operação estão relacionados com volume, velocidade de secagem e temperatura do ar.

O objetivo do trabalho é analisar os métodos utilizados e seus efeitos na manutenção da qualidade fisiológica das sementes.

\section{MATURAÇÃO DAS SEMENTES E A NECESSIDADE DE SECAGEM}

A tecnologia para a produção de sementes preconiza, genericamente, a realização da colheita no

\footnotetext{
${ }^{1}$ Trabalho extraído da Tese de Doutorado do primeiro autor apresentada à Universidade Federal de Pelotas (UFPel) em março de 2001 . ${ }^{2}$ Engenheiro Agrônomo, Professor Adjunto, Doutor, Departamento de Fitotecnia, Centro de Ciências Rurais (CCR), Universidade Federal de Santa Maria (UFSM), 97105-900, Santa Maria-RS,

E-mail: danton@ccr.ufsm.br. Autor para correspondência

${ }^{3}$ Engenheiro Agrônomo, Professor Adjunto, Doutor, Depto. de Fitotecnia, Faculdade de Agronomia Eliseu Maciel (FAEM), UFPel, CP 354, 96010-900, Pelotas, RS.

${ }^{4}$ Engenheiro Agrônomo, PhD., Professor Titular, Departamento de Fitotecnia, FAEM, UFPel.

${ }^{5}$ Engenheiro Agrônomo, Professor Adjunto, Doutor, Depto. de Fitotecnia,CCR, UFSM.
} 
momento mais próximo possível da maturidade fisiológica. Sabe-se, entretanto, que as sementes, de uma maneira geral, atingem a maturidade fisiológica com teores de água superiores a 30\%, não compatível, com a tecnologia disponível para a colheita mecânica (VILLELA\& SILVA, 1992; PESKE \& BARROS, 1997; MIRANDA et al.,1999).

A maturação das sementes é uma fase que compreende as transformações morfológicas, fisiológicas e funcionais que se iniciam no momento da fertilização do óvulo e terminam com o acúmulo máximo de matéria seca (POPINIGIS, 1985). Este estádio é definido como o ponto de maturidade fisiológica e, genericamente, é considerado o momento em que as sementes desligam-se da planta-mãe e apresentam seu maior potencial de qualidade, indicado pelo maior peso de matéria seca, germinação e vigor.

Desde a maturidade fisiológica até o momento de sua utilização na semeadura, as sementes estão sujeitas à perda da qualidade fisiológica pelas mudanças bioquímicas e fisiológicas que passam a ocorrer. A deterioração, em muitos casos imperceptível na fase inicial, manifesta-se no decorrer do tempo, ocasionando reflexos negativos no vigor. Segundo MORAES (2000), a rapidez com que ocorre a perda de qualidade das sementes após a maturidade fisiológica é função da espécie, da cultivar e das condições impostas às sementes no campo, após a colheita e durante as operações de beneficiamento e armazenamento.

De um modo geral, é possível afirmar que a qualidade das sementes decresce a partir da maturidade fisiológica, dependendo das condições climáticas, principalmente, temperatura e umidade relativa do ambiente em que ficam expostas, até atingir o momento de colheita.

Segundo AHRENS \& PESKE (1994), os mecanismos de sorção e dessorção diários de água em sementes de soja, entre a maturidade fisiológica e o momento de colheita, podem alcançar amplitude superior a cinco pontos percentuais, em decorrência das variações da umidade relativa do ambiente. Tal fato, mesmo que em intensidade variável, pode ocorrer para outras espécies, considerando que as sementes estão em permanente intercâmbio de água com o ambiente.

Assim, a higroscopicidade das sementes determina sua capacidade de estar em permanente troca de água com a atmosfera que a rodeia. A predominância do fluxo de água é determinado pelo gradiente de potencial hídrico entre as sementes e o ar atmosférico. Quando a diferença de potencial é nula, cessa o processo de transferência de água e as sementes entram em equilíbrio higroscópico com o meio. As sementes e a atmosfera que as rodeiam, são sistemas que se encontram em permanente troca de água, com sentido preferencial definido pela diferença de potencial hídrico existente entre ambos. A predominância de fluxo hídrico ocorre do sistema que se encontra com maior potencial para o menor até ser atingido o ponto de equilíbrio higroscópico (SILVA, 1986).

No Brasil, nas últimas décadas, surgiu a necessidade do desenvolvimento de trabalhos de pesquisa sobre secagem, com o objetivo de aprimorar a tecnologia de produção de sementes. Quando a pesquisa em tecnologia de sementes intensificou-se e a indústria de equipamentos recebeu incentivos, surgiram os primeiros trabalhos relacionados com secagem.

A secagem artificial vem sendo utilizada como uma operação de rotina nas empresas de sementes, principalmente, nos estados do Sul do Brasil e, não obstante as vantagens que apresenta, é uma operação de risco, podendo proporcionar danos irreversíveis se realizada sem os conhecimentos e cuidados necessários à preservação da qualidade inicial das sementes (CARVALHO, 1994; MIRANDA et al. 1999).

BAUDET et al. (1999) sugerem a secagem como um processo fundamental da tecnologia para a produção de sementes de alta qualidade, pois permite a redução do teor de água em níveis adequados para o armazenamento, preserva as sementes de alterações físicas e químicas, induzidas pelo excesso de umidade, e torna possível a manutenção da qualidade inicial durante o armazenamento, possibilitando colheitas próximas da maturidade fisiológica.

\section{PRINCÍPIOS DE SECAGEM}

A secagem demanda existência de gradientes de pressões parciais de vapor de água entre as sementes e o ar de secagem. De acordo com as propriedades higroscópicas, o fluxo de vapor de água ocorre no sentido da maior para a menor pressão parcial de vapor; assim, o aquecimento do ar de secagem determina a redução da umidade relativa e o conseqüente aumento do potencial de retenção de água. A secagem de sementes, mediante convecção forçada do ar aquecido, estabelece dois processos que ocorrem simultaneamente: transferência da água superficial das sementes para o ar e movimento de água do interior para a superfície das sementes, decorrente do gradiente hídrico entre essas duas regiões (VILLELA, 1991; MORAES, 2000). 
A secagem também pode ser entendida como um processo simultâneo de transferência de calor do ar para as sementes e de massa (água) das sementes para o ar. Assim, em função da necessidade de energia térmica para a evaporação da água, ocorre um resfriamento do ar de secagem pela perda de calor sensível. No entanto, o balanço energético é nulo porque o ar recupera, na forma de vapor de água (calor latente), o que perdeu na forma de calor sensível. Desse modo, a secagem é considerada um processo isoentálpico, em que ocorre redução da temperatura do ar e aumentos da razão de mistura, da umidade relativa, da pressão de vapor e da temperatura do ponto de orvalho; por outro lado à entalpia e a temperatura do bulbo úmido permanecem praticamente constantes (VILLELA \& SILVA, 1992; CAVARIANI, 1996).

\section{MÉTODOS DE SECAGEM}

Os métodos de secagem são classificados quanto ao uso de equipamentos (natural ou artificial), à periodicidade no fornecimento de calor (contínuo ou intermitente) e à movimentação da massa de sementes (estacionário ou contínuo).

A secagem natural é baseada nas ações do vento e do sol para a remoção da umidade das sementes. Tal processo é limitado pelo clima, quando as condições de umidade relativa do ar e temperatura não permitem, ou quando se trata de maiores volumes de sementes. Apesar de apresentar baixo custo, é um método lento, e as sementes não devem ser expostas em camadas superiores a 4-6cm, com revolvimento periódico (MAIA, 1995). Apresenta desvantagens que decorrem do intensivo uso de mão-de-obra, uma vez que as operações geram baixo rendimento e o processo é totalmente dependente das condições climáticas disponíveis (CARVALHO, 1994).

Na secagem artificial, a fonte de calor pode ser variável. O que caracteriza um método como artificial é o fato de que o processo é executado com o auxílio de alternativas mecânicas, elétricas ou eletrônicas e o ar, que atravessa a massa de sementes, é forçado (CAVARIANI, 1996). Apresenta as vantagens de permitir o controle da temperatura, do fluxo do ar de secagem e do tempo de exposição das sementes ao ar aquecido, fatores fundamentais para garantir a eficiência do processo.

Baseada na capacidade do ar fornecer calor e na necessidade de aumentar a temperatura do ar, segundo VILLELA (1991), a secagem artificial pode ser dividida em duas categorias: secagem em baixa temperatura, na qual se utiliza o ar natural ou aquecido de 1 a $8^{\circ} \mathrm{C}$ acima da temperatura ambiente e secagem em alta temperatura, que consiste em aquecer o ar a temperaturas iguais ou superiores a $8-10^{\circ} \mathrm{C}$ acima da temperatura ambiente.

Quanto ao fluxo de sementes no interior do equipamento de secagem, os métodos artificiais podem ser classificados em contínuo e estacionário.

A secagem em fluxo contínuo implica manter as sementes em constante movimento no interior do secador. Na secagem contínua, as sementes passam através do secador apenas uma vez, ficando expostas um determinado período ao ar aquecido e outro na câmara de resfriamento. Isso vale dizer que as sementes entram úmidas na câmara de secagem e são descarregadas resfriadas com a umidade desejada. Nessas condições, a massa de sementes atinge temperaturas elevadas, ficando expostas aos danos térmicos, que podem causar redução na viabilidade e no vigor (AGUIRRE \& PESKE, 1992; VILLELA \& SILVA, 1992; CARVALHO, 1994).

Embora não seja recomendado para a secagem de sementes, esse método pode ser utilizado, desde que observadas algumas precauções. VILLELA \& PESKE (1997) sugerem a elevação da velocidade do fluxo das sementes permitindo o aumento do número de passagens pela câmara de secagem, reduzindo, dessa forma, o tempo de exposição ao ar aquecido e mantendo a temperatura da massa de sementes em níveis não prejudiciais para manutenção de sua qualidade.

Uma outra alternativa que vem sendo avaliada é a utilização do método contínuo adaptado para secagem de sementes. O mesmo consiste na utilização de secadores que apresentam, no mínimo, duas câmaras de secagem. MOTTA (1997), avaliando o método para secagem de sementes de arroz, indicou que temperaturas do ar máximas de $60^{\circ} \mathrm{C}$ e $50^{\circ} \mathrm{C}$, respectivamente nas câmaras superior e inferior podem ser empregadas, obtendo-se lotes que apresentam elevada qualidade fisiológica.

A secagem intermitente é caracterizada pela permanência das sementes em contato com o ar aquecido por períodos curtos, intercalados com períodos sem exposição ao fluxo de ar aquecido na câmara de equalização.

0 período de equalização possibilita a redistribuição da umidade no interior das sementes, reduzindo os gradientes hídrico e térmico (VILLELA \& PESKE, 1997). Na secagem intermitente, o período de equalização permite aumentar a quantidade de água removida por unidade de tempo em relação à secagem contínua. Isso decorre do fato da velocidade de secagem, após a remoção da água superficial, ser 
determinada pela velocidade de transporte da água, do interior para a superfície das sementes. Esse sistema ainda pode ser classificado, de acordo com a razão entre o período de exposição das sementes ao ar aquecido e o período de equalização (relação de intermitência), em intermitente rápido e lento (BAUDET et al.,1999).

No intermitente rápido, a relação de intermitência, em geral, é de 1:6, a 1:15, ou seja, para cada período de exposição ao ar aquecido, é necessário um período de equalização 6 a 15 vezes maior. Por outro lado, no método intermitente lento, a razão de intermitência pode ser de 1:1 a 1:3, dependendo do modelo de secador (LUZ \& PESKE, 1988; VILLELA \& PESKE, 1997).

A secagem intermitente de sementes permite a utilização de temperaturas elevadas do ar de secagem, sem contudo aumentar, excessivamente, a temperatura da massa de sementes devido ao período de equalização. Isso reduz os riscos de provocar danos térmicos, tornando-se mais eficiente que os outros sistemas, pois a quantidade de água extraída, por unidade de tempo, é maior (VILLELA, 1991; BAUDET et al., 1999).

A secagem estacionária consiste em forçar o fluxo de ar através de uma camada de sementes, que permanece estática no interior do secador, normalmente, um silo com fundo falso perfurado; neste caso a secagem ocorre da base para o topo da camada de sementes ou em um silo, com tubo central perfurado, que permite a distribuição do fluxo de ar do centro para a periferia.

A secagem estacionária ocorre em camadas, em função da formação da frente de secagem, que correspondem às regiões de intercâmbio de água entre as sementes e o ar. Na região anterior à frente de secagem, as sementes permanecem secas e a temperatura é maior e, na região posterior, tem-se sementes úmidas e baixa temperatura. Nesse método de secagem, a pressão estática ou, perda de pressão, refere-se à resistência imposta ao deslocamento do ar forçado ao atravessar a massa de sementes, como conseqüência de perdas de energia por fricção e turbulência. Depende da arquitetura dos dutos, do fluxo de ar, das características físicas da cobertura protetora das sementes, do volume e arquitetura dos espaços porosos e da uniformidade da massa de sementes (MORAES, 2000). 0 fluxo de ar deve ser de 4 a $20 \mathrm{~m}^{3} / \mathrm{min} / \mathrm{t}$, a umidade relativa não deve ser inferior a $40 \%$ e a temperatura do ar não deve ultrapassar $43^{\circ} \mathrm{C}$ (AGUIRRE \& PESKE, 1992).

De acordo com CAVARIANI (1996), a taxa de secagem expressa o percentual de água retirado das sementes em função do tempo e está relacionada com a movimentação da água, do interior para a superfície das sementes que, por sua vez, é dependente do genótipo, do estádio de maturação, do teor de água, da permeabilidade da camada protetora, da composição física do lote de sementes, da temperatura, da umidade relativa, do fluxo do ar e do método de secagem. A velocidade de secagem pode também ser função da composição química das sementes, e do método utilizado no processo.

Resultados obtidos por BOUNOUS (1986), empregando o método intermitente lento, indicaram que as curvas de secagem de sementes de azevém anual são expressas linearmente e que a taxa de secagem, verificada nas temperaturas de 50 e $80^{\circ} \mathrm{C}$, com fluxo de ar de $86 \mathrm{~m}^{3} / \mathrm{min} / \mathrm{t}$, foram de 1,7 e 1,9 pontos percentuais por hora, respectivamente. Por outro lado, LUZ \& PESKE (1988), utilizando o mesmo método de secagem em sementes de arroz, com teor de água inicial entre 20,7 e 17,2\%, verificaram que a taxa de secagem à temperatura de $70^{\circ} \mathrm{C}$ foi constante de 1,8 pontos percentuais por hora.

VILLELA \& SILVA (1992) determinaram a curva de secagem para sementes de milho, utilizando secador intermitente com temperatura do ar de $80^{\circ} \mathrm{Ce}$ concluíram que o teor de água decresceu linearmente com o tempo, na razão de 0,66 pontos percentuais por hora para teores de água entre 15,8 e 13,1\%.

Um outro método utilizado é a seca-aeração. Esse originalmente foi concebido para a secagem de grãos de milho, sendo posteriormente utilizado para sementes.

A seca-aeração elimina o período de resfriamento no secador, transferindo as sementes ainda aquecidas para um silo, onde serão resfriadas com fluxos de ar de 0,3 a $1,0 \mathrm{~m}^{3} / \mathrm{min} / \mathrm{t}$. Nesse tipo de secagem, o próprio calor armazenado nas sementes é utilizado para provocar a migração de umidade, reduzindo o tempo de secagem com fonte de calor externo, o que pode provocar uma redução da ordem de 20 a $40 \%$ de energia, e aumento da capacidade de secagem de 50 a $75 \%$, quando comparado com a secagem de fluxo contínuo (DALPASQUALE et al., 1987).

ZIMMER et al. (1992) indicaram que este método de secagem não afetou, de imediato, a qualidade fisiológica das sementes de arroz, enquanto, RODRIGUEZ (1988) indicou que o fluxo de ar deve ser no mínimo de $0,6 \mathrm{~m}^{3} / \mathrm{min} / \mathrm{t}$, sendo que o fluxo de $0,3 \mathrm{~m}^{3} /$ $\mathrm{min} / \mathrm{t}$ provocou deterioração das sementes, após 120 dias de armazenamento.

A secagem com ar ambiente forçado é um método simples, porém, somente viável em regiões ou épocas de clima seco quando as condições de umidade 
relativa do ar são inferiores àquelas em que as sementes alcançam o equilíbrio, ou seja, 70 e $75 \%$. Se esse sistema for devidamente projetado e manejado, poderá tornarse econômica e tecnicamente eficiente, uma vez que possibilita a obtenção de um produto seco e de alta qualidade (QUEIROZ \& PEREIRA, 1982).

Em geral, a secagem com ar ambiente forçado propicia melhor qualidade de sementes. No entanto, na tomada de decisão, o produtor deve fazer uma análise criteriosa dos custos, pois se trata de um processo lento que requer 4 a 8 semanas, é limitado à umidade inicial de 22 a $24 \%$ e a secagem e o armazenamento ocorrem no mesmo silo, minimizando a manipulação de sementes.

\section{DANOS TÉRMICOS}

Durante o processo de secagem, as sementes sofrem mudanças físicas, provocadas por gradientes de temperatura e umidade, que ocasionam expansão, contração e alterações na densidade e porosidade. $\mathrm{O}$ processo de secagem não aumenta o percentual de sementes quebradas, mas pode provocar fissuras internas ou superficiais, tornando as sementes mais suscetíveis à quebra durante o beneficiamento (VILLELA, 1991).

Segundo CAVARIANI (1996), a causa primária do dano produzido por altas temperaturas em tecidos vegetais é a desintegração das membranas celulares, possivelmente, por alterações nos lipídios que as constituem. Também é aceita a teoria de que a temperatura excessivamente alta pode provocar, entre outras alterações, a desnaturação de proteínas. Os danos fisiológicos provocados pela secagem podem se refletir em alterações nos sistemas subcelulares, incluindo cromossomas e mitocôndrias, na redução do número de grãos de amido no eixo embrionário, em aumentos de lixiviação de eletrólitos e açúcares e de produção de pigmentos carotenóides, redução de permeabilidade de membranas celulares e taxa respiratória.

A sensibilidade fisiológica ao dano térmico é função da espécie, genótipo, teor de água, temperatura, tempo de exposição e velocidade de secagem. Estes danos podem gerar fissuras, capazes de tornar as sementes facilmente quebradiças nas operações de beneficiamento, além de interferir nos mecanismos de trocas hídricas e gasosas e aumentar a predisposição ao ataque de insetos e microorganismos (SOAVE \& MORAES, 1987; MOTTA, 1997).

A manifestação do dano térmico pode ser verificada através da análise de germinação, pela presença de plântulas anormais, redução na porcentagem e velocidade de germinação, pela análise de fissuras internas, principalmente em arroz, ou superficiais em milho (HARRINGTON, 1972; NELLIST \& HUGHES, 1973).Os danos térmicos podem não manifestar efeitos imediatos na germinação, contudo, após um período de armazenamento, o vigor das sementes pode sofrer reduções consideráveis (POPINIGIS, 1985).

\section{CONSIDERAÇÕES FINAIS}

Pelo exposto e, tendo em vista a importância da secagem de sementes, devem-se buscar métodos alternativos de secagem, como por exemplo, a combinação dos métodos discutidos, substituição de combustíveis na busca de menor preço e baixa degradação ambiental e melhorias nos sistemas atuais no que diz respeito ao rendimento térmico, buscando reduzir os custos de secagem com aumento da eficiência energética do processo e preservação dos recursos do meio ambiente.

A secagem de sementes é um tema complexo e, na maioria das vezes, as instalações disponíveis são as possíveis e não as ideais. Além disso, em muitos casos, os sistemas de secagem são obrigados a operar fora do seu regime normal para que a unidade de beneficiamento de sementes, como um todo, possa maximizar sua performance. Assim, tornase importante que os operadores tenham consciência das condições de secagem que conseguem proporcionar às sementes, buscando minimizar ao máximo as inevitáveis e irreversíveis perdas que ocorrem a partir do momento que as sementes atingem sua máxima qualidade fisiológica.

\section{REFERÊNCIAS BIBLIOGRÁFICAS}

AGUIRRE, R.; PESKE, S.T. Manual para el beneficio de semillas. 2.ed. Cáli, Colômbia : CIAT. 1992. 248p.

AHRENS, D.C.; PESKE, S.T. Flutuações de umidade e qualidade de sementes de soja após a maturação fisiológica. I. Avaliação do teor de água. Revista Brasileira de Sementes, Brasília, v.161, n.2, p.107-110,1994.

BAUDET, L.M.L.; VILLELA, F.A.; CAVARIANI, C.Princípios de secagem. Seed News, Pelotas-RS, n.10, p. 20-27, 1999.

BOUNOUS, E.B. Comparação de métodos de secagem em sementes de azevém anual (Lolium multiflorum L.). 1986. 109f. Dissertação (Mestrado em Ciência e Tecnologia de Sementes) - UFPel.

BROOKER, D.B.; BAKKER-ARKEMA, F.W.; HALL, C.W. Drying cereal grains. Westport : AVI , 1981. 265p. 
CARVALHO, N.M. A secagem de sementes. J aboticabal : FUNEP, 1994. 165p.

CAVARIANI, C. Secagem estacionária de sementes de milho com distribuição radial do fluxo de ar. 1996. 85 f. Tese (Doutorado em Produção Vegetal) - Esalq-USP.

DALPASQUALE, V.A. et al. Secagem de grãos em altas temperaturas. Viçosa : CETREINAR, 1987. 47p.

HARRINGTON, J.F. Seed storage and logevity. In: KOZLOWSKI, T.T. Seed biology. New York : Academic, 1972. V.3, p.145-245.

LUZ, C.A.S.; PESKE, S.T. Secagem de arroz em secador intermitente lento. Revista Brasileira de Sementes, Brasília, v.10, n.2, p.103-114,1988.

MAIA, M. Secagem de sementes de azevém anual (Lolium multiflorum Lam.) com ar ambiente forçado. 1995. 108f. Tese (Doutorado em Ciência e Tecnologia de Sementes) - UFPel.

MIRANDA, L.C.; DA SILVA,W.R.;CAVARIANI,C. Secagem de sementes de soja em silo com distribuição radial do fluxo de ar. I. Monitoramento físico. Pesq agropec bras, Brasília, v.34, n.11, p.2097-2108, 1999.

MORAES, M.L.B de. Comportamento da pressão estática e da frente de secagem em uma coluna de sementes de arroz. 2000. 50f. Tese (Doutorado em Ciência e Tecnologia de Sementes) -UFPel.

MOTTA, W.A. Adaptação do método contínuo de secagem para sementes de arroz. 1997. 58f. Dissertação (Mestrado em Ciência e Tecnologia de Sementes) - UFPel.

NELIST, M. E.; HUGHES, M. Physical and biological processes in the drying of seed. Seed Science and Technology, Zurich: v.1, n1, p.613-643,1973

PESKE, S.T. ; BARROS, A.C.S.A. Produção de sementes de arroz. In: PESKE, S.T.; NEDEL, J.L.; BARROS, A.C.S.A. Produção de arroz irrigado. Pelotas : UFPel. 1997. p. 351412.

POPINIGIS, F. Fisiologia da semente. Brasília, 1985. 289 p.

QUEIROZ, D.M.; PEREIRA, J.A.M. Secagem a baixa temperatura. Viçosa : UFV, CETREINAR, 1982. 30p

RODRIGUEZ, G.G. Efeitos da seca-aeração no armazenamento de sementes de milho sobre sua qualidade fisiológica. 1988. 60f. Dissertação (Mestrado em Ciência e Tecnologia de Sementes) - UFPel.

SILVA, W. R. Secagem das sementes. In: CICERO, S.M.; MARCOS FILHO, J. Atualização em produção de sementes. Campinas : Fundação Cargill, 1986. p.155-182.

VILLELA, F.A. Efeitos da secagem intermitente sobre a qualidade de sementes de milho. 1991. 104f. Tese (Doutorado em Produção Vegetal) - Esalq-USP.

VILLELA, F.A ; SILVA, W.R. Curvas de secagem de sementes de milho utilizando o método intermitente. Scientia Agricola, Piracicaba, v.49, n.1, p.145-153,1992.

VILLELA, F.A ; PESKE, S.T. Tecnologia pós-colheita para arroz. In: PESKE, S.T.; NEDEL, J.L.; BARROS, A.C.S.A. Produção de arroz irrigado. Pelotas : UFPel, 1997. p. 351412 .

ZIMMER, G.J. et al. Aeração seca para sementes de arroz. Pesq agropec bras, Brasília, v.27, n.9, p.1371-1378, 1992. 